\title{
An Electrochemical Immunosensor for the Detection of B-Type Natriuretic Peptide (BNP) Based on Sandwich ELISA Using Screen Printed Carbon Electrodes
}

\author{
Yeni Wahyuni Hartati ${ }^{1 *}$, Muhammad Hilman Daniswara ${ }^{1}$, Ratna Nurmalasari ${ }^{2}$, Shabarni Gaffar ${ }^{1}$, Toto \\ Subroto ${ }^{1}$ \\ ${ }^{1}$ Department of Chemistry, Faculty of Mathematics and Natural Sciences, Universitas Padjadjaran, Jatinangor, \\ Bandung, West Java, Indonesia \\ ${ }^{2}$ Department of Health Analysis, Sekolah Tinggi Analis Bakti Asih, Cimenyan, Bandung, West Java, Indonesia \\ *email: yeni.w.hartati@unpad.ac.id
}

Received August 25, 2017; Accepted March 18, 2018; Available online May 31, 2018

\begin{abstract}
B-type natriuretic peptide (BNP) is a 32-amino acid polypeptide, a cardiac neuro hormone that specifically secreted from heart ventricle as a response towards the increase of volume and pressure in the heart. The determination of BNP concentration in patients blood is one of the method used to diagnose heart failure. An electrochemical immunosensor modified with the streptavidin/biotin system on screen printed carbon electrodes for the detection of the BNP antigen was developed in this study. Monoclonal anti-BNP capture antibody was immobilized on streptavidin-modified SPCEs to give a well oriented of antibody. Furthermore, a biotinylated anti-BNP that conjugated with horseradish peroxidase (HRP) was used as secondary antibody. The electrochemical signal produced by redox activity of substrate 3,3,5,5'-tetramethybezidine dihydrochloride $\left(\mathrm{TMB} / \mathrm{H}_{2} \mathrm{O}_{2}\right)$ was measured by differential pulse voltammetry. The BNP immunosensor showed a linear response between $1.0 \times 10^{-2}$ and $1.0 \times 10^{2}$ $\mathrm{ng} / \mathrm{mL}$, and the limit of detection was $3.3 \mathrm{ng} / \mathrm{mL}$. BNP immunosensor is a promising technology for the rapid and convenient detection of heart failure.
\end{abstract}

Keywords: B-type natriuretic peptide, electrochemical immunosensor, screen printed carbon electrodes, voltammetry

\section{INTRODUCTION}

B-type natriuretic peptide (brain natriuretic peptide; BNP) is a cardiac hormone with diuretic, natriuretic, and vasodilator properties. This 32amino acid polypeptide contains a 17- amino acid ring structure common to all natriuretic peptides and is secreted mainly in the ventricles in response to volume expansion and pressure load (Koch and Singer, 2003; Maeng et al., 2012). BNP concentrations are elevated in patients with cardiac abnormalities and are associated with the severity of heart disease (Mueller et al., 2007). BNP was found with an average concentration of $8.6 \pm 8.2 \mathrm{ng} / \mathrm{L}$ in blood plasma, of the 56 normal adults, in newborn infants decreased significantly from $231.6 \pm 197.5$ to $48.4 \pm 49.1 \mathrm{ng} / \mathrm{L}(\mathrm{p}=$ 0.001). Meanwhile BNP was found with higher concentrations, in patients with left ventricular dysfunction hearts, there were found BNP concentration of $380.07 \pm 991.1 \mathrm{ng} / \mathrm{L}$ of 50 patients (Koch and Singer, 2003; Clerico et al., 1998). Determination of BNP concentrations became quite useful as the one of the first diagnostic ways of heart failure (Longenecker et al., 2009).

Immunoassay with electrochemical detection is more attractive than the spectrophotometric method, because the detection limit is low, ease of operation and the analyze time is fast (Al-Khafaji et al., 2012). Electrochemical immunosensors using anti-BNP antibodies can be used for clinical trials or imaging of heart failure. Maeng et al, 2012 had used recombinant antibody fragment, anti BNP$\mathrm{scFv}$ expressed in Pichia pastoris, as an element biorecognition to detected BNP by electrochemical immunoassay using gold electrodes. Interestingly, these method exhibited excellent analytical performance with a detection limit of $1 \mathrm{fg} / \mathrm{ml}$ and a wide linear detection range that was from 1 to $10,000 \mathrm{fg} / \mathrm{mL}$. A label-free immunosensor platform based on excessively tilted fiber gratings (Ex-TFGs) was developed for detection of human N-terminal pro-B-type natriuretic peptide (NT-proBNP) with LOD of $\sim 0.5 \mathrm{ng} / \mathrm{mL}$. The average sensitivity for NTproBNP at a concentration range of $0 \sim 1.0 \mathrm{ng} / \mathrm{mL}$ 
was approximately $45.967 \mathrm{ng} / \mathrm{mL}$ (Luo et al., 2017). The sensitivity of the immunosensor is strongly influenced by the orientation of the immobilized antibody on the electrode surface (Parkash et al., 2015). Ordinarily, when the antibody molecule is immobilized on a solid surface such as an electrode, the antibody will lose its biological binding activity due to a change in the side which exposed to the solution (Ronkainen et al., 2008). There are several methods to immobilize an antibody on the surface of electrode, such as direct physical adsorption, covalent binding, polymer trapping, microencapsulation, and crosslinking methods (Gomes et al., 2009; Lomillo et al., 2010). The attachment of antibody to the electrode surface through the specific streptavidin/biotin molecular interaction has been revealed as an effective and reliable approach. Streptavidin is a tetrameric protein, with equivalent subunits that can bind to one biotin molecule. The streptavidin-biotin system can be utilized a good orientation of antibody during the immobilization process, therefore the antibody determining region can be freely interact with the antigen (Hu et al., 2014).

In this study, we developed BNP immunosensors based on sandwich enzyme-linked immunosorbent assay (ELISA) system by using screen printed carbon electrode (SPCE), as the schematic was described in Hartati et al (2017). Streptavidin-biotin system was used as a linker to immobilized biomolecule to the electrode surface. We performed streptavidin immobilization on the surface of electrode by direct physical adsorption method. Moreover, the application of these SPCE is mainly based on their attractive advantages such as disposability and ease of preparation. In the present experiment, the experimental parameters affecting the responses of the sensor were optimized in terms of the conjugate concentration and incubation time on the competitive assay.

\section{EXPERIMENTAL SECTION}

\section{Instruments}

Differential pulse voltammetry was carried out using potensiostat Metrohm $\mathbb{R}$ Autolab type III connected to PC with NOVA software (Metrohm, Switzerland), and BiPotensiostat/Galvanostat DropSens $\mu$ STAT 400 are connected to the DropView 800 software
(Dropsens, Switzerland). The SPCEs DRP110 were used consisted of an $\mathrm{Ag} / \mathrm{AgCl}$ as reference electrode, carbon electrode as an auxiliary electrode and working electrode (Dropsens), mini spin (Eppendorf), weighing balance (Mettler Toledo AL204), pH meter (Mettler Toledo InLab $\mathrm{pH}$ combination polymer elecrodes) micro (Eppendorf), micro tube and tip of micro pipette, autoclave sterilizer (Hirayama Autoclave HVE50), Scanning electron microscopy (SEM) images type JSM-6360LA (Japan).

\section{Materials}

Bovine serum albumin (BSA), potassium chloride $(\mathrm{KCl})$, Dipotassium hydrogen phosphate $\left(\mathrm{K}_{2} \mathrm{HPO}_{4}\right)$, potassium dihydrogen phosphate $\left(\mathrm{KH}_{2} \mathrm{PO}_{4}\right)$, sodium chloride $(\mathrm{NaCl})$, ferricyanide $\left[\mathrm{Fe}(\mathrm{CN})_{6}\right]^{3-}$, and phosphate buffer solution (PBS) pH 7.4 (Sigma Aldrich). Streptavidin, biotinylated anti-BNP, horseradish peroxidase (HRP) labelled anti BNP, TMB, BNP antigen were purchased from Abcam, United Kingdom.

\section{Methods}

The schematics of methods were immobilization of streptavidin, and then attach to biotinylated anti-BNP. Anti-BNP will interact with BNP in samples. The process of interaction anti-BNP with BNP is electrochemically detected based on electron transfer reactions of HRPlabelled secondary antibodies with TMB substrate (Hartati et al., 2017).

\section{Immobilization of the anti-BNP}

A solution of $20 \mu \mathrm{L}$ streptavidin (50 $\mu \mathrm{g} / \mathrm{mL}$ ) was immobilized on pretreated SPCE. The SPCE were incubated overnight at $4{ }^{\circ} \mathrm{C}$. After washing using PBS, $20 \mu \mathrm{L} / \mathrm{mL}$ of biotinylated anti-BNP $(5 \mu \mathrm{g} / \mathrm{mL})$ that prepared in $0.01 \mathrm{M}$ PBS was incubated on the electrode surface for $1 \mathrm{~h}$, then the surface was washed by immersing SPCEs into PBS (0.01 M; pH 7.4). Later, non-specific bindings were blocked by incubating the electrode surface with BSA $1 \%$ for 15 min.

\section{Characterization of Prepared Electrodes}

To determine whether streptavidin, antiBNP-biotin and BNP have been successfully immobilized or not, electrode characterization was performed using SEM and by an indirect method. SPCE before and after modification with each step of immobilized immunoreagens addition is measured by cyclic voltammetry using a redox 
system of $10 \mathrm{mM}$ potassium ferricianide solution in $\mathrm{KCl} 0.1 \mathrm{M}$ in the potential range -0.6 to 1.0 Volt with a scan rate of $0.05 \mathrm{Volt} / \mathrm{second}$.

\section{Selection of the Conjugate Concentration and Incubation Time}

Anti-BNP-biotin with a concentration of 5.0 $\mu \mathrm{g} / \mathrm{mL}$ and $10.0 \mu \mathrm{g} / \mathrm{mL}$ were tested on immunosensor to obtain the best biotinylated of anti-BNP concentration. Selection is done by using the same streptavidin, BSA, and BNP concentrations. In addition, selection of the best incubation time for BNP and anti-BNP-HRP was also conducted for 30 and 60 seconds.

\section{Immunosensor Response to BNP}

After successful immobilization of the antiBNP capture antibody, various dilutions of BNP antigen prepared in $0.01 \mathrm{M}$ PBS $\left(1.0 \times 10^{-2}\right.$ to $1.0 \times 10^{2} \mathrm{ng} / \mathrm{mL}$ ) were added onto the electrodes surface and left to react with the anti-BNP capture antibody for $1 \mathrm{~h}$, then the surface was washed by immersing SPCEs into PBS (0.01 M; pH 7.4). The assay was then completed by pipetting $20 \mu \mathrm{L}$ of ( 5 $\mu \mathrm{g} / \mathrm{mL}) \quad$ HRP-labeled anti-BNP detection antibody. Finally, the electrodes were washed prior to electrochemical measurement.

\section{Measurement Procedure for Electrochemical Responses}

All the electrochemical responses were performed at room temperature. Electrochemical measurements were carried out by placing a $50 \mu \mathrm{L}$ TMB solution onto the electrode, covering the three electrodes area. Differential pulse voltammetric measurements were carried out by scanning at $50 \mathrm{mV} \cdot \mathrm{s}^{-1}$ and potential ranging from -0.6 Volt to 1.0 Volt.

\section{RESULTS AND DISCUSSION}

Streptavidin gets attach to the surface of the electrode by passive adsorption, due to the hydrophobic and hydrophilic interactions between the electrode surface (carbon-based) and the positive charge of amine group of streptavidin. Streptavidin is a protein consisting of four equivalent subunits; each subunit can bind specifically to one biotin molecule. [Streptavidin is used to direct primary anti-BNP antibodies with proper orientation because the constant fragments of these antibodies have been conjugated with biotin. Figure 1 shows the surface of SPCE before and after modified by streptavidin. Then the electrode was washed using PBS pH 7.4 for five seconds]. This washing by PBS is performed after each addition of immunoreagen and aims to remove non-specific floating species that are not attached to the electrode surface. Streptavidin will attach to biotinylated of anti-BNP on the surface of the electrode. The biotinylated of anti-BNP will identify 27-32 amino acid residues in the Cterminal region of the BNP chain. Figure 1A shows a bare SPCE profile, visible large pores on its surface. Figure 1B shows after streptavidin immobilization, with the same magnification seen the surface of the SPCE covered with streptavidin molecules. The Figure 1C shows a larger molecular attachment of the biotinylated of anti$\mathrm{BP}$, visible blobs that cover the electrode surface. This means that each immunoreagen can attach well to the eectrode surface. The attachment of anti-BNP on SPCE with streptavidin-biotin system has been characterized by observing cyclic voltammograms of the redox activity of electroactive species $\left[\mathrm{Fe}(\mathrm{CN})_{6}\right]^{3-}$.

Figure 2 shows cyclic voltammograms of $\mathrm{K}_{3}\left[\mathrm{Fe}(\mathrm{CN})_{6}\right] 10 \mathrm{mM}$ in a $0.1 \mathrm{M} \mathrm{KCl}$ solution on SPCE. The decrease in peak current after a modified electrode by streptavidin shows that streptavidin immobilization on the SPCE surface has been successful, since the presence of streptavidin on the surface causes the impediment of electron transfer between $\left[\mathrm{Fe}(\mathrm{CN})_{6}\right]^{3-}$ and electrode. Likewise after anti-BNP-biotin attachment decreases the peak current because $\left[\mathrm{Fe}(\mathrm{CN})_{6}\right]^{3-} \quad$ further away from the electrode surface, consequently the electron transfer is getting blocked. Anodic and cathodic peak declines also occur when BSA and BNP have been immobilized.

To ensure the electrochemical current peak pattern of TMB was measured by differential pulse voltammetric for each reagent as shown in Figure 3. Voltammograms showed that prior to the redox process of TMB that caused by attachment of BNP as an analyte with HRPlabelled secondary antibody, no peak current was produced.

The optimization of the measurement conditions is shown in Figure $\mathbf{4}$ including concentration of anti-BNP and incubation time, also HRP-anti-BNP and its incubation time. Figure 4A shows the anti-BNP-biotin 
concentration of $5.0 \mu \mathrm{g} / \mathrm{mL}$ yielded higher current (4.29 times vs. blank) than the concentration of $10.0 \mu \mathrm{g} / \mathrm{mL}$ (2.62 times vs. blank). At a concentration of $10.0 \mu \mathrm{g} / \mathrm{mL}$, the antibodies immobilized on the electrode surface are over saturated, interfering with the immobilization process and resulting in poor immobilization orientation, reducing the amount of anti-BNPbiotin attached to streptavidin. Figure 4B describes that 30 minute incubation time provides a lower current response because the added BNP antigen has not been attached completely to antiBNP-biotin, nor is the anti-BNP-HRP added yet attached to the BNP. Incubation times over 60 minutes were considered too long and less efficient for use in routine analysis in clinical trials.

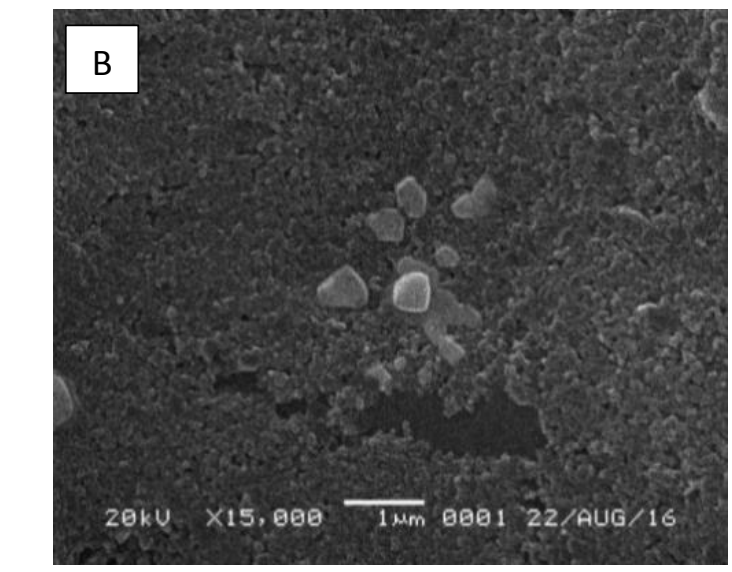

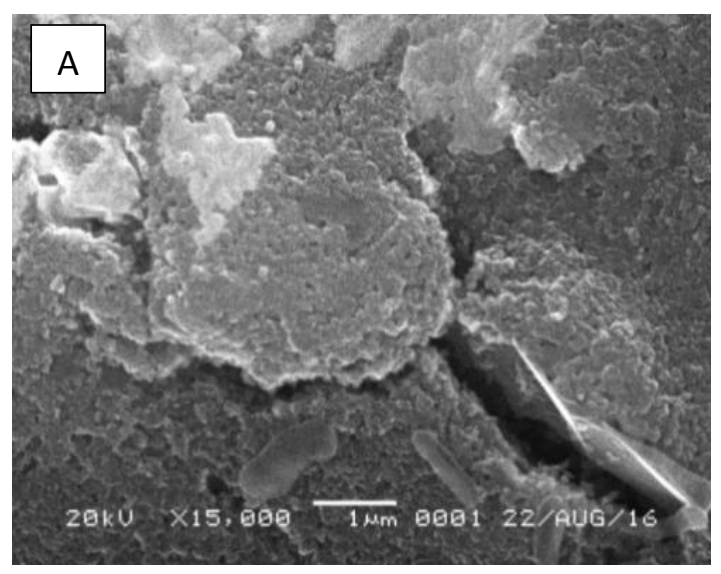

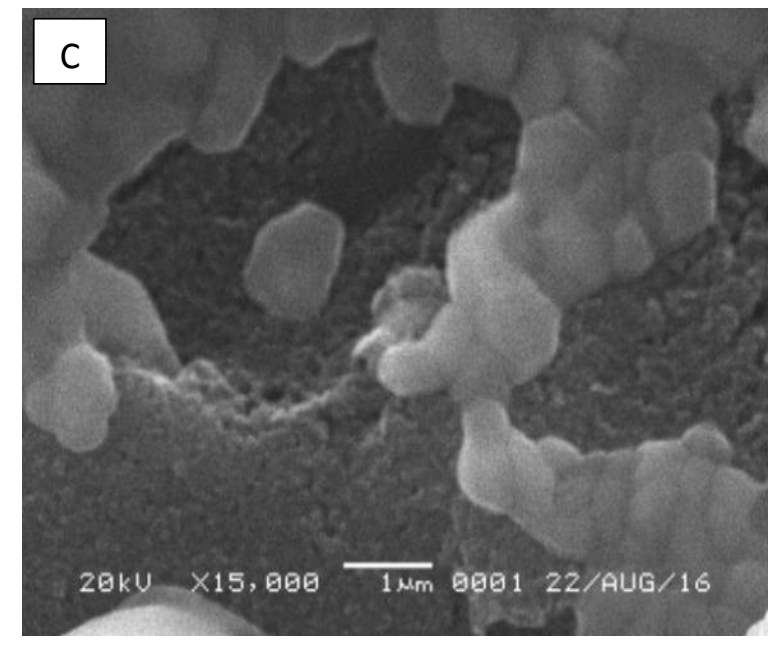

Figure 1. SEM surface image of (A) bare SPCE, (B) SPCE with streptavidin overnight immobilized, (C) SPCE-streptavidin/anti-BNP biotinylated 


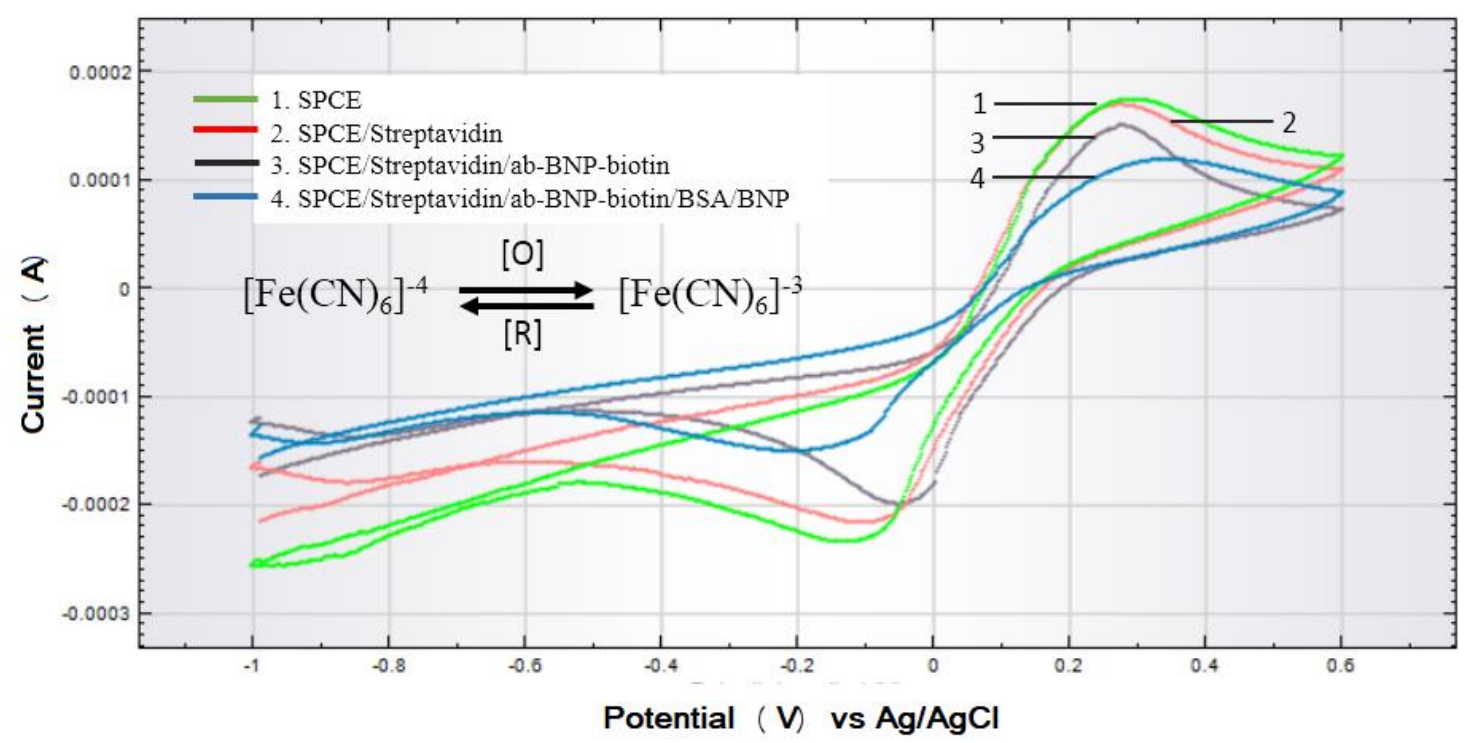

Figure 2. Cyclic voltammograms of unmodified and modified SPCE. Scan rate $50.0 \mathrm{mV} / \mathrm{s}$ in $10.0 \mathrm{mM}$ $\mathrm{K}_{3} \mathrm{Fe}(\mathrm{CN})_{6}$ containing $100.0 \mathrm{mM} \mathrm{KCl}$.

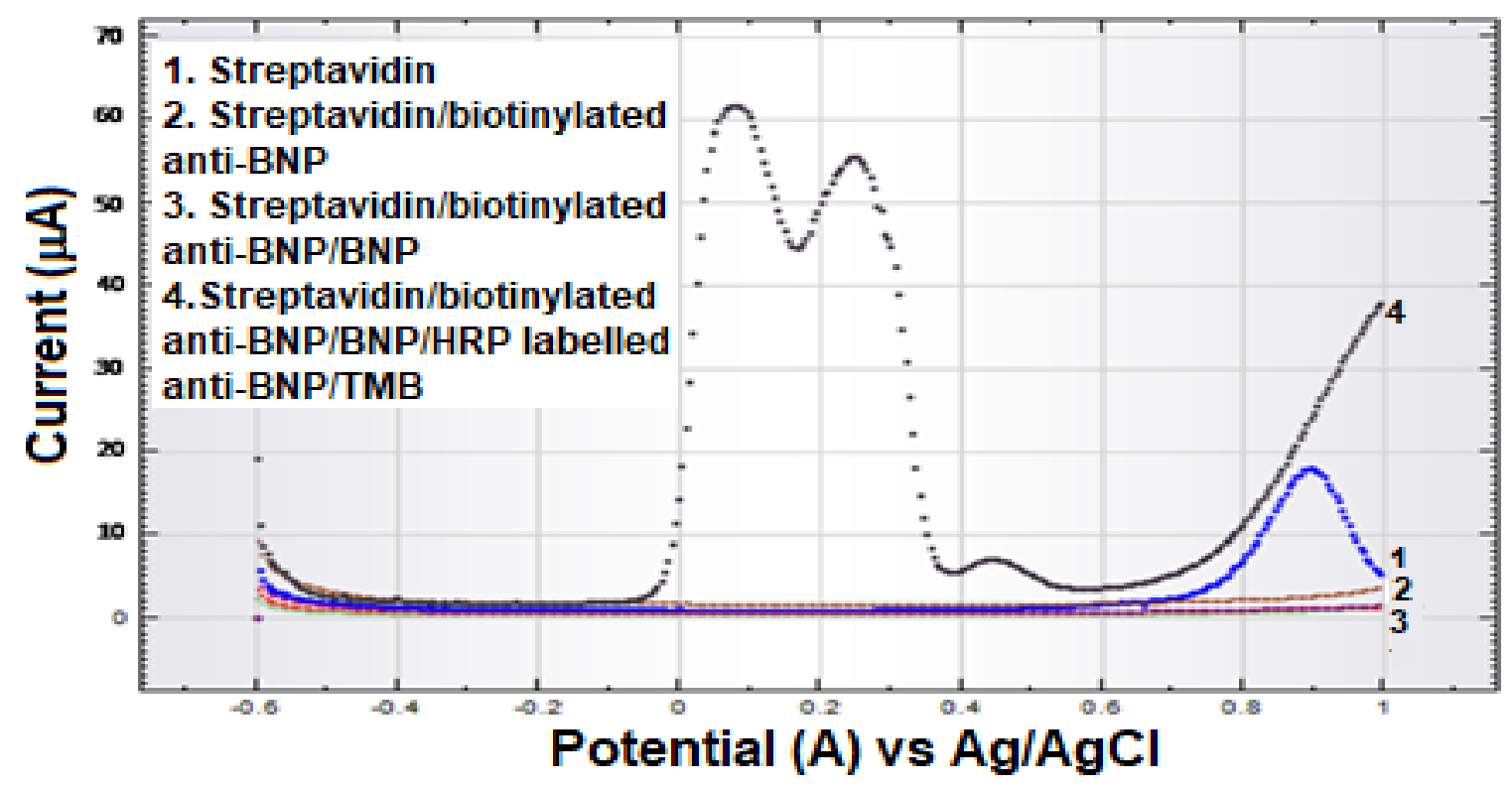

Figure 3. Differential pulse voltammograms of unmodified and modified SPCE. Scanning potential -0.6 to $+1.0 \mathrm{~V}$. Scan rate $50.0 \mathrm{mV} / \mathrm{s}$. 

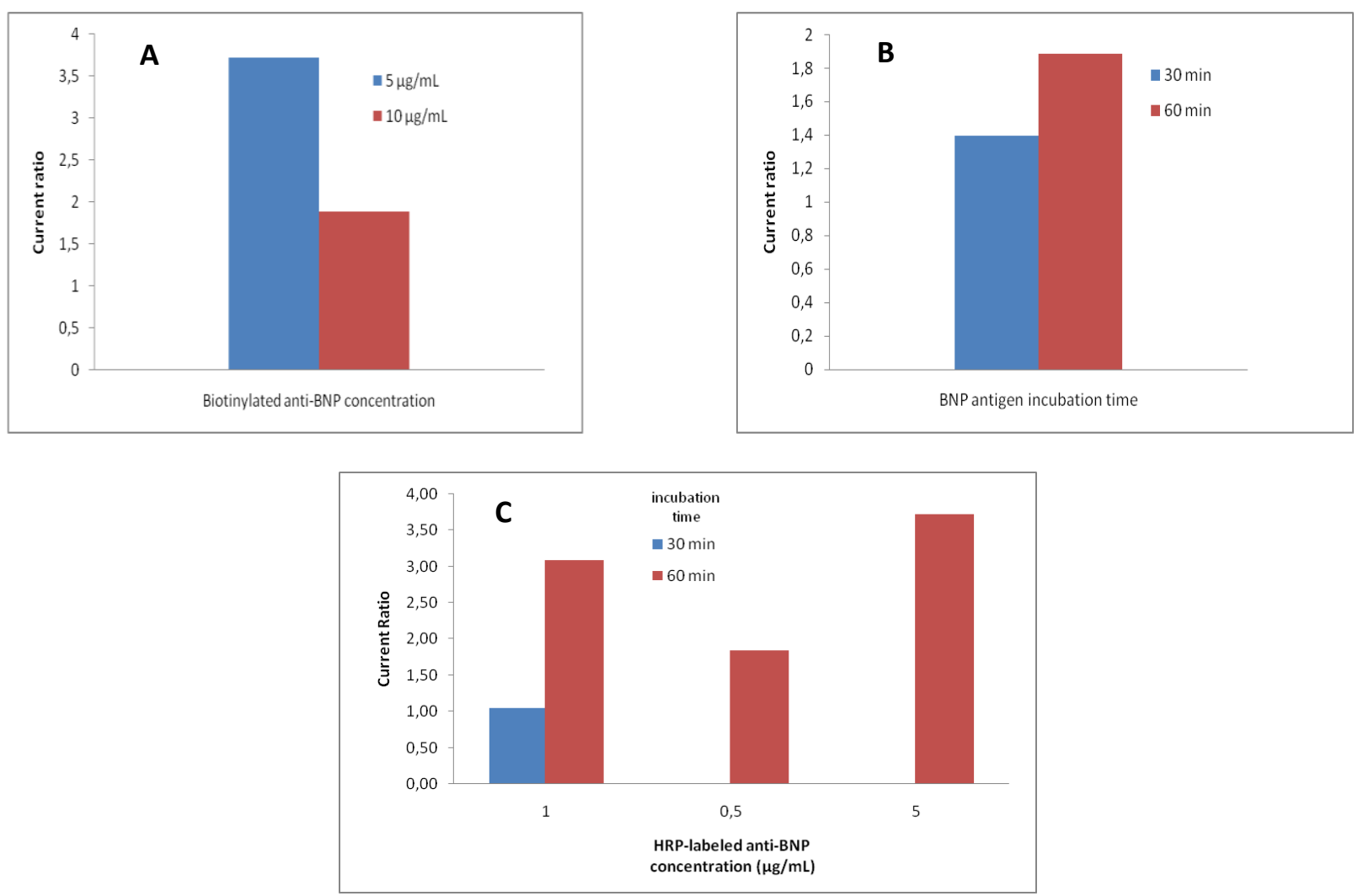

Figure 4. (A) Selection of the best biotinylated anti-BNP concentration (B) Selection of BNP antigen incubation time (C) Selection of HRP labelled anti BNP concentration and incubation time.

The current ratio were signal (BNP antigen $1.0 \mathrm{ng} / \mathrm{mL}) /(\mathrm{BNP}$ antigen $0.0 \mathrm{ng} / \mathrm{mL})$. Anti-BNP-HRP is also important in the development of immunosensors, as they relate to the sensitivity of immunosensor detection to BNP. Figure 4C describe the anti-BNP-HRP concentration $5.0 \mu \mathrm{g} / \mathrm{mL}$ yielded higher current (4.29 times vs. blank) than the concentration of $1.0 \mu \mathrm{g} / \mathrm{mL}$ (3.09 times vs. blank), and $0.1 \mu \mathrm{g} / \mathrm{mL}$ (1.84 times vs blank).

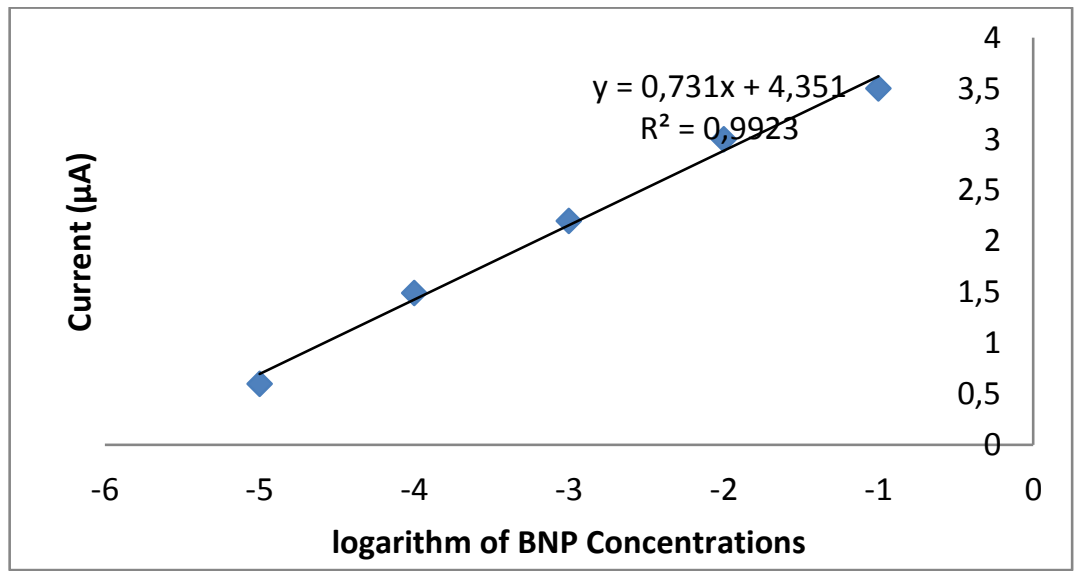

Figure 5. Calibration curve of peak current $v s$ logarithm of BNP antigen concentration. Calibration curve was obtain by using anti-BNP $5.0 \mu \mathrm{g} / \mathrm{mL}, \mathrm{BNP}$ antigen $0.0,10.0 \mathrm{pg} / \mathrm{mL}-0.1 \mu \mathrm{g} / \mathrm{mL}$ using DPV on modified SPCE. Scanning potential -0.6 to $+1.0 \mathrm{~V}$ and scan rate $50.0 \mathrm{mV} . \mathrm{s}^{-1}(\mathrm{n}=3)$. 
At concentrations lower than $5.0 \mu \mathrm{g} / \mathrm{mL}$, the number of anti-BNP-HRPs that detect BNP is lacking, and the added anti-BNP-HRP does not bind all the BNPs present in the sample, the antibonded HRP enzyme-BNP-HRP can also lose its catalytic activity significantly when dilution with too low concentration $(0.1 \mu \mathrm{g} / \mathrm{mL})$ results in a low signal response and does not correspond to the number of BNP. Determination of best concentration of anti-BNP-HRP was done only at incubation time for 60 minutes because it was seen peak current was higher at incubation time for 60 minutes for concentration $1.0 \mu \mathrm{g} / \mathrm{mL}$.

The linear relationship between the peak current height and the concentration of BNP antigen in various concentration variations is shown in Figure 5. The results showed a linear response to the logarithm of concentration of BNP antigen with high peak current generated in the concentration range between $1.0 \times 10^{-2}, 1.0 \times 10^{-1}$, $1.0,1.0 \times 10^{1}$ and $1.0 \times 10^{2} \mathrm{ng} / \mathrm{mL}$ with the value $\mathrm{R}^{2}=$ 0.99 . The limit of detection limit of $3.3 \mathrm{ng} / \mathrm{mL}$.

\section{CONCLUSIONS}

This approach of electrochemical immunosensor for the detection of the BNP antigen is based on the immobilization of capture antibodies via the streptavidin/biotin system on SPCEs resulted in well-oriented immobilization of the capture antibody. The analytical performance of with a limit of detection $3.3 \mathrm{ng} / \mathrm{mL}$ and a wide linear detection range of $1.0 \times 10^{-2}$ to $1.0 \times 10^{2} \mathrm{ng} / \mathrm{mL}$ were found. This immunosensor can be applied to real samples, and can distinguish normal or heart failure.

\section{ACKNOWLEDGEMENTS}

The Authors acknowledge the financial support from Academic Leadership Grant Program, Universitas Padjadjaran 2016 and Penelitian Unggulan Perguruan Tinggi (PUPT) 2016 Kementrian Riset Teknologi dan Pendidikan Tinggi, Indonesia.

\section{REFERENCES}

Al-Khafaji, Q.A.M., Harris, M., Tombelli, S., S. Laschi, S., Turner, A., Mascini, M., Marrazza, G. (2012) an electrochemical immunoassay for HER3 detection.
Electroanalysis. (24),4: 735-742. http://dx.doi.org/10.1002/elan.201100501

Clerico, A., Lervasi G., Del Chicca M.G., Emdin M., Maffei S., Nannipieri M., Sabatino L., Forini F., Manfredi C., \& Donato L (1998) Circulating Level of Cardiac Natriuretic Peptides (ANP and BNP) Measured by Highly Sensitive and Spesific Immunoradiometric Assay in Normal Subjects and in Patients with Different Degreees of Heart Failure. Journal Endocrinal. 21:170-179.

Gomez, V.E., Campuzano S., Maria P., \& Jose M. P. (2009) Gold Screen-printed-based Impedimetric Immunobiosensors For Direct and Sensitive Escherichia Coli Quantization. Biosensors and Bioelectronics Journal. 24:33653371.https://doi.org/10.1016/j.bios. 2009.04.047.

Hartati, Y.W,R Nurmalasari, $\underline{\mathrm{S} \text { Gaffar, }} \underline{\mathrm{T} \text { Subroto. }}$ (2017), B-Type Natriuretic Peptide (BNP) Detection Using Electrochemical Immunosensor Based On Sandwich ELISA With Horseradish PeroxidaseTetramethylbenzidine System. Procedia Technology, 27:149150.https://doi.org/10.1016/j.protcy.2017.0 4.065 .

$\mathrm{Hu}$, Chunmei, Wenchao Dou, \& Guangying Zhao. (2014), Enzime Immunosensor Based on Gold Nanoparticles Electroposition and Streptavidin-biotin System for Detection of S. pullorum \& S. gallinarum. Electrochimca Acta. 117: 239245.https://doi.org/10.1016/j.electacta.2013. $\underline{11.132}$

Koch, A and Singer, H. (2003) Normal values of B type natriuretic peptide in infants, children, and adolescents Heart.; 89(8): 875-878.

Longenecker, K. L., Ruan, Q., Fry, E. H., Saldana, S. C., Brophy, S. E., Richardson, P. L. and Tetin, S. Y. (2009), Crystal structure and thermodynamic analysis of diagnostic $\mathrm{mAb}$ 106.3 complexed with BNP 5-13 (C10A). Proteins, 76: 536-547. doi:10.1002/prot.22366.

Lomillo, M.A.A., Renedo O.D., \& Martínez M.J.A. (2010), Screen-printed Biosensors In Microbiology; A Review. Talanta 
journal.

$82: 1629$

1636.https://doi.org/10.1016/j.talanta.2010. 08.033

Luo, B., S Wu, Z Zhang, W Zou, S Shi, M Zhao, N Zhong, Y Liu, XZou, L Wang, W Chai, C Hu, L Zhang. (2017),Human heart failure biomarker immunosensor based on excessively tilted fiber gratings. Biomedical Optics Express. Volume 8: 57-67. https://doi.org/10.1364/BOE.8.000057

Maeng B.H., Choi J., Young S.S., Shin J.H., \& Kim Y.H. (2012), Functional expression of recombinant anti BNP-ScFv in methylotrophic yeast Pichia pastoris and application as a recognition molecule in electrochemical sensors. World Journal Microbiol. Biotechnol. 28:1027-1034.
Mueller C., Breidthardt T., Laule-Kilian K., Christ M., \& Perruchoud A.P.(2007), The integration of BNP and NT-proBNP into clinical medicine. N. Swiss Journal Med .137:4-12.

Parkash O., Chan Y.Y., \& Rafidah H.S. (2014), Screen Printed Carbon Electrode Based Electrochemical Immunosensor For the Detection of Dengue NS1 Antigen. Diagnostics.4:165-180. doi:10.3390/diagnostics4040165

Ronkainen, N.J., Halsall H.B., \& Heineman W.R. (2008), Electrochemical biosensors. Chemical Society Reviews. http://pubs.rsc.org | doi:10.1039/B714449K. 